\title{
КИНЕТИКА ФОТОИНИЦИИРОВАННОЙ ДЕГРАДАЦИИ НЕКОТОРЫХ МЕТИЛПРОИЗВОДНЫХ БЕНЗ(а)ПИРЕНА
}

В состав загрязняющих биосферу продуктов, выбросов и отходов деятельности человека входит широкий набор полициклических ароматических углеводородов (ПАУ), значительная часть которых обладает выраженной канцерогенной активностью. Важным элементом в процессе их деградации при самоочищении среды являются превращения, стимулируемые световым, в частности ультрафиолетовым, излучением при доступе кислорода и в его отсутствии. Некоторые исследователи рассматривают эти реакции как основу метаболического превращения канцерогенных веществ, попадающих в организм $\left[{ }^{1,2}{ }^{2}\right]$, или как системы, отдаленно имитирующие такие процессы [3]. Поэтому изучение кинетики и механизма деградации канцерогенных ПАУ, активированной УФ-излучением, и, в первую очередь, сопоставление реакционной способности последних с особенностью строения их молекул и физиологической активностью представляют существенный интерес в практическом и теоретическом аспектах.

В серии наших предыдущих работ $\left[{ }^{4}\right]$ дана как раздельная, так и совместная макрокинетическая характеристика фотохимической деградации наиболее типичного из канцерогенных ПАУ - бенз(а) пирена * - (б(а) п) с физиологически инактивными ПАУ сходной природы - пиреном и бенз(е)пиреном. В итоге удалось составить представление о характере реакций, протекающих при фотодеградации бенз(а)пирена, и вероятном механизме активации его молекул с последующим переносом электронной энергии к соседним молекулам растворителя.

Продолжением наших исследований в указанном направлении является изучение кинетики фотоинициированной деградации некоторых моно- и демитилпроизводных бенз(а)пирена. Известная их доля, очевидно, сопутствует основному канцерогену в технических загрязнениях. Установлено также [4,5], что некоторые из них являются продуктами фотодеградации бенз(а)пирена при иопользовании в жачестве растворителей соединений, подверженных фотодиссоциации с образованием свободных метильных радикалов (ацетон, метанол, этанол). К сожалению, сведения из литературы о метилпроизводных бенз(а)тирена ограничиваются лишь констатацией их канцерогенной активности $\left[{ }^{6-5}\right.$.

Настоящее исследование является звеном в научном сотрудничестве советских и французских исследователей, работающих в области физико-химии канцерогенных ПАУ.

\section{Объекты и методика исследования}

С целью получения данных для сравнения в сопоставимых условиях исследованию подвергнуты собственно бенз(а)пирен, а также два монометил- и три диметилпроизводных бенз(а)пирена с различным располо-

* В отличие от предыдущих сообщений мы прибегаем к этому обозначению (вместо 3,4-бензпирен), как получившему наибольшее распространение в последние годы. 
жением заместителей в. молекуле. Структура исследованных соединений охарактеризована в табл. 1.

\section{Таблица 1}

I Бенз(а)тирен

11 1.Метнлбенз (а) пирен

III 6-Метилбенз (а) пирен

IV - 1,8-Диметилбенз (а) пирен

V. 5,10-Диметилбенз (а) пирен

VI 5,8-Диметилбенз (а)лирен

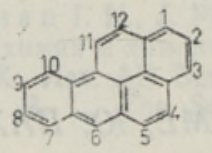

$\mathrm{CH}_{3}$
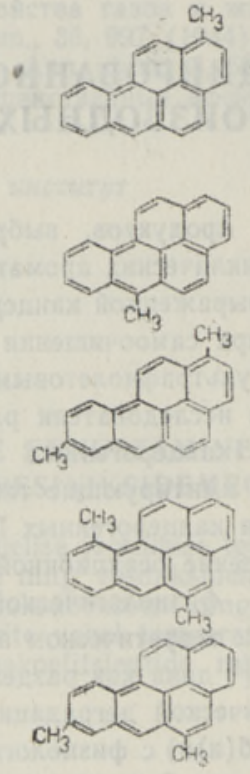

Предварительно для всех указанных соединений I-VI измерены квазилинейчатые спектры флуоресценции и возбуждения [9], что позволяет определить частоты нормальных колебаний в основном и возбужденном состояниях и энергию первого возбужденного синглетного состояния молекул. Измерения произведены с растворами I-VI в $н$-гексане или н-октане (концентрация ПАУ $5 \cdot 10^{-6}$ моль/ $)$ при температуре жидкого азота $77^{\circ} \mathrm{K}$. Для возбуждения флуоресценции использована лампа ДКсШ-1000 и монохроматор МДР-1, регистрация ее произведена на установке Института физики и астрономии АН ЭССР с помощью монохроматора ДФС-12 и системы счета фотонов с записью на самописце ЭПП-09, описанных в [10].

Процесс фотоинициированной деградации осуществляется в установке, описанной в наших предыдущих сообщениях, с облучением образцов в широком волновом диапазоне свыше $200 \mathrm{~mm}$ (лампа типа СВД-120-А, максимум испускания в области 360 нм) при интенсивности $1,2 \cdot 10^{16} \kappa в а н т / \mu л \cdot с е \kappa$ и температуре $25 \pm 1,0^{\circ} \mathrm{C}$. Растворителем является бензол, концентрация ПАУ $(c)$, за исключением опытов с III, поддерживается на уровне $2 \cdot 10^{-4}$ моль/л. Первый цикл экспериментов проведен при неограниченном доступе кислорода в систему, а второй, при прочих неизменных условиях, в атмосфере аргона.

В работе использованы следующие реактивы: бензол для УФ-спектроскопии (фирма «Chemapol»); бенз (а)пирен чистый (фирма «Fluka AG, Buchs SG»); все метилпроизводные бенз(а)пирена, кроме III, синтезированы в лаборатории Н. П. Буу Хой Института химии природных соединений Национального центра научных исследований Франции (Жиф-сюрИветт) и, по рекомендации авторов, подвергнуты нами дополнительной очистке; 6-метилбенз(а)пирен получен в результате препаративного выделения из смеси продуктов фотодеградации бенз(а)пирена, растворенного в ацетоне.

Концентрация метилпроизводных бенз(а) пирена в реакционной смеси в ходе кинетических опытов определена по спектрам поглощения (рис. 1), которые сняты на спектрофотометре СФ-4M или Specord UV VIS (ГДР), при внесении поправки с учетом фона. Значения коэффициента молярной экстинкции для соединений I и III взяты из [11]. 


\section{Результаты исследования и их обсуждение}

Первичная обработка полученных экспериментальных данных представлена на рис. 2 кинетическими кривыми фотоинициированной деградации 1,8-диметилбенз(a) пирена (IV) при доступе кислорода и в атмосфере аргона. Аналогичная закономерность установлена и для деградации остальных изученных ПАУ.

В обоих циклах суммарный процесс фотопревращения изучаемых соединений описывается макрокинетическим уравнением нулевого
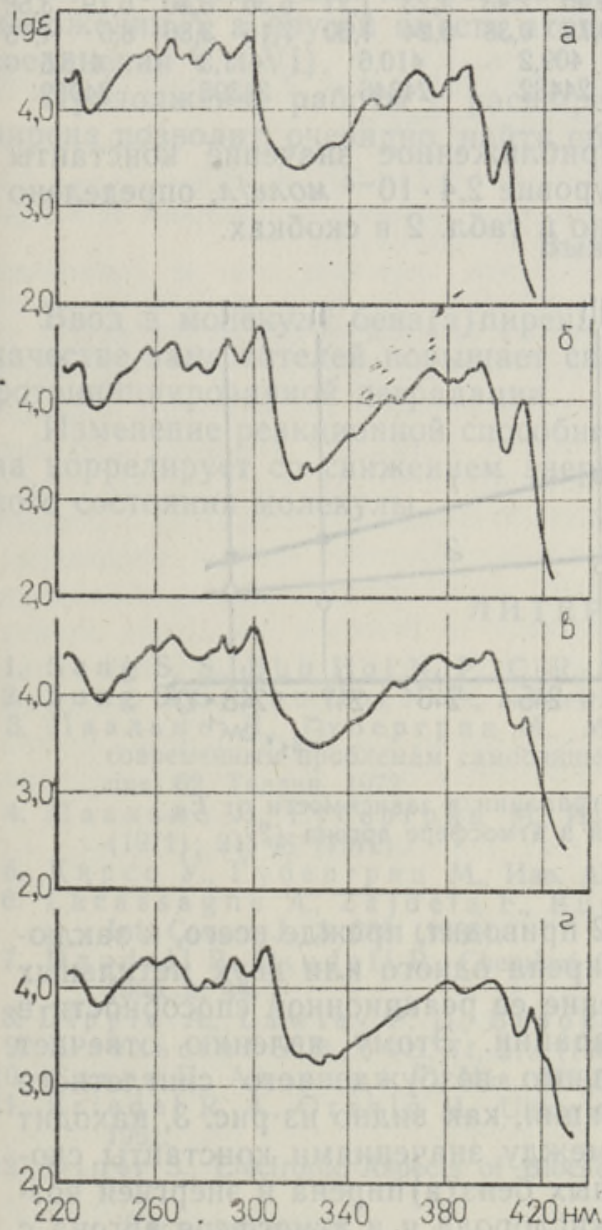

Рис. 1. Спектры поглощения в этаноле: $a-1$-метилбенз(а) пирен $404(3,67), 388$ $(4,45), 368(4.38), 350(4.10): 5-1.8$. диметилбенз (a)пирен $410 \quad(4,02), \quad 394$ $(4,40), 374(4.35), 356(4.66) ; 8-5,10$. диметилбенз(а)пирен $412 \quad(3,78), \quad 398$ $(4,48), 376(4,42), 358(4,13) ;$ г $-5,8$-днметилбенз(а)пирен $414(3,8), 400(4,07)$, $378(4,07)$.

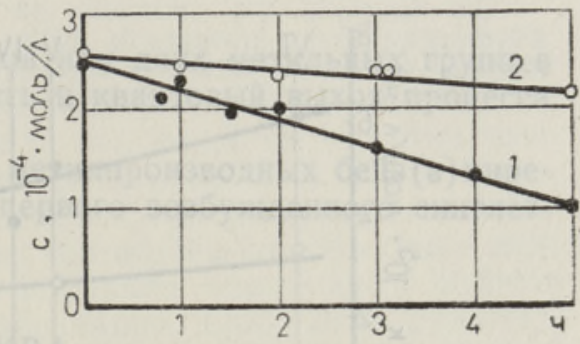

Рис. 2. Кинетические кривые фотодегра дации 1,8-диметилбенз(а)пирена в присутствии кислорода (I) и в атмосфере aproна (2)

порядка при расчете по убыли исходного ПАУ. На этом основании определены значения константы скорости суммарной реакции $(k)$, квантового выхода (Ф) и так наз. константы деградации $\left(k^{\prime}\right)$ или молярной степени превращения исходного вещества в единицу времени с размерностьюсек ${ }^{-1}$. Результаты соответствующих расчетов приведены в табл. 2 в сопоставлении с энергией первого синглетного состояния молекулы, которая отвечает чисто электронной линии $0-0$ перехода $\left(\lambda_{0-0}\right)$ в спектре флуоресценции. Кинетические показатели в этой таблице расположены в порядке убывания величины $E_{S_{1}}$. Подробное рассмотрение результатов измерения квазилинейчатых спектров возбуждения и флуоресценции для указанного набора ПАУ и их интерпретация являются предметом специального сообщения.

При рассмотрении данных табл. 2 следует иметь в виду, что эксперимент с III, которым мы располагаем в весьма малом количестве, проведен при сниженной на один порядок концентрации его в растворе по

3 ENSV TA Toimetised K* G -11973 
Фотодеградация метилпроизводных бенз(а)пирена

\begin{tabular}{|c|c|c|c|c|c|c|c|c|c|c|c|c|}
\hline \multirow{3}{*}{$\begin{array}{c}\text { Наименование } \\
\text { показателей }\end{array}$} & \multicolumn{12}{|c|}{ Соединение (см. табл. 1) } \\
\hline & \multicolumn{2}{|c|}{ I } & \multicolumn{2}{|c|}{ II } & \multicolumn{2}{|c|}{ III } & \multicolumn{2}{|c|}{ IV } & \multicolumn{2}{|c|}{ V } & \multicolumn{2}{|c|}{ VI } \\
\hline & $\mathrm{O}_{2}$ & $\mathrm{Ar}$ & $\mathrm{O}_{2}$ & $\mathrm{Ar}$ & $\mathrm{O}_{2}$ & $\mathrm{Ar}$ & $\mathrm{O}_{2}$ & $\mathrm{Ar}$ & $\mathrm{O}_{2}$ & $\mathrm{Ar}$ & $\mathrm{O}_{2}$ & $\mathrm{Ar}$ \\
\hline $\begin{array}{l}c, \text { моль/л } \cdot 10^{-4} \\
k, \text { моль } / \Omega \cdot u \cdot 10^{-5}\end{array}$ & $\begin{array}{l}3,0 \\
2,58\end{array}$ & $\begin{array}{l}3,0 \\
1,89\end{array}$ & $\begin{array}{l}2,4 \\
2,91\end{array}$ & $\begin{array}{l}2,4 \\
1,50\end{array}$ & \multirow{2}{*}{$\begin{array}{c}0,3 \\
0,51 \\
(4,0) \\
4,46 \\
0,72 \\
409 \\
244\end{array}$} & \multirow{2}{*}{$\begin{array}{l}0,3 \\
0.26 \\
(2,3) \\
2,43 \\
0,38 \\
, 2 \\
32\end{array}$} & & $\begin{array}{l}2,5 \\
1,07\end{array}$ & $\begin{array}{l}2,2 \\
5,10\end{array}$ & $\begin{array}{l}2,3 \\
2,76\end{array}$ & $\begin{array}{l}2,7 \\
6,07\end{array}$ & $\begin{array}{l}2,7 \\
3,39\end{array}$ \\
\hline $\begin{array}{l}k^{\prime}, \text { сек-1 } \cdot 10^{-5} \\
\Phi, \text { молек/квант } \cdot 10^{-4} \\
\lambda_{0-0}, \text { нм } \\
E_{S_{1}}, \text { сM }^{-1}\end{array}$ & $\begin{array}{l}2,37 \\
3,62 \\
403 \\
2480\end{array}$ & $\begin{array}{l}1,74 \\
2,65 \\
3,0 \\
07\end{array}$ & $\begin{array}{r}3,36 \\
4,08 \\
40 \\
247\end{array}$ & $\begin{array}{l}1,84 \\
2,1 \\
4,5 \\
15\end{array}$ & & & $\begin{array}{r}4,23 \\
5,24 \\
410 \\
243\end{array}$ & $\begin{array}{l}1,21 \\
1,50 \\
, 6 \\
46\end{array}$ & $\begin{array}{r}5,36 \\
7,15 \\
41 \\
243\end{array}$ & $\begin{array}{l}3,40 \\
3,86 \\
1,3 \\
05\end{array}$ & $\begin{array}{l}6,19 \\
8,5 \\
41 \\
240\end{array}$ & $\begin{array}{l}3,50 \\
4,75 \\
5,5 \\
59\end{array}$ \\
\hline
\end{tabular}

сравнению с остальными опытами. Приближенное значение константы скорости $k$, для концентрации III на уровне $2,4 \cdot 10^{-4}$ моль $/ \Omega$, определено расчетом из зависимости $k$ от $k^{\prime}$ и дано в табл. 2 в скобках.

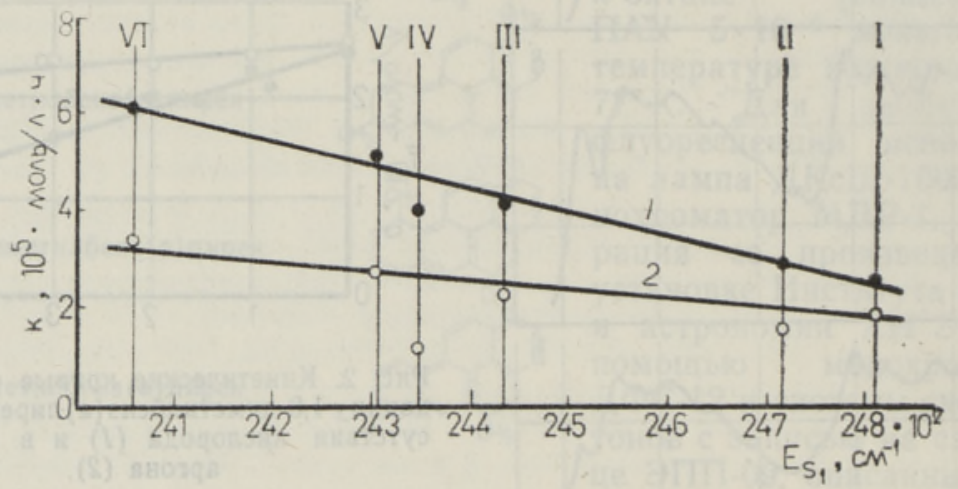

Рис. 3. Константа скорости фотодеградашии в зависимости от $E_{S}$ в присутслвии кислорода $(l)$ и в атмосфере аргона (2).

Дальнейший анализ данных табл. 2 приводит, прежде всего, к заключению, что ввод в молекулу бенз(а) пирена одного или двух метильных заместителей влечет за собой увеличение ее реакционной способности в процессах фотоинициированной деградации. Этому явлению отвечает тенденция к снижению энергии первого возбужденного синглетного состояния молекулы. Указанная тенденция, как видно из рис. 3 , находит проявление в линейной зависимости между значениями константы скорости фотодеградации метилпроизводных бенз(а)пирена и энергией возбужденного состояния в присутствии кислорода и в атмосфере аргона с коэффициентами корреляции соответственно 0,92 и 0,93. Из корреляции исключена точка для деградации IV в аргоне, отклонение которой на основании материалов настоящего исследования не может получить объяснения.

В группе монометилпроизводных наибольшей реакционной способностью отличается 6-метилбенз(а)пирен (III), в котором метильный радикал привязан к атому углерода с наибольшим индексом свободной валентности $\left[{ }^{12}\right]$. Для него характерно и наибольшее снижение значения $E_{S_{1}}$ и соответственно наибольший сдвиг максимума поглощения $\alpha$-полосы. 
В группе диметилпроизводных с замещением водорода у двух атомов углерода, для которых сумма индексов свободной валентности имеет близкое значение $(0,86-0,89)$, причину различий в реакционной способности в зависимости от энергии $E_{S_{1}}$ установить не удается. Судя по полученным данным для диметилпроизводных, замещение водорода одним из метильных радикалов у атома углерода в положении 5, т. е. у одного из пары, составляющей область «К» в молекуле канцерогена, чревато возрастанием реакционной способности (см., например, сведения из табл. 2 для IV и VI соединений). Трудно объяснить причину аналогичного увеличения реакционной способности и снижения $E_{S_{1}}$ для молекулы, в которой один из метильных радикалов привязан к углероду в положении 5 , а другой вместо атома 10 перемещен в положение 8 (см. соединения V и VI).

Продолжение работы с расширением набора производных бенз(а)пирена позволит, очевидно, найти объяснение указанным явлениям.

\section{Выводы}

Ввод в молекулу бенз(а)пирена одной или двух метильных групп в качестве заместителей повышает скорость и квантовый выход процесса фотоинициированной деградации.

Изменение реакционной способности метилпроизводных бенз(а)пирена коррелирует со снижением энергии первого возбужденного синглетного состояния молекулы.

\section{ЛИТЕРАТ УРА}

1. Sung S. S., Buu Hoi N. P., C. R. Acad. Sci. (Paris), 270D, 2052 (1970).

2. Sung S. S., B u u Ho i N. P., Naturwissenschaiten, 57, 135 (1970).

3. Паальме Л., Губергри ц М., Материалы IV Всесоюзного симпозиума по современным проблемам самоочищения и регулирования качества воды, II секция, 62, Таллин, 1972.

4. П а альме Л., Губбергриц М., Изв. АН ЭССР, Хим. Геол., 20, 31, 127, 220 (1971); 21, 48 (1972).

5. Кирсо У., Губергриц М., Изв. АН ЭССР, Хим. Геол., 20, 138 (1971).

6. Lacassagne A., Z a jdela F., Bu u Hoi N. P., Chalvet O., Daub G. H., Int. Cancer J., 3, 238 (1968).

7. D a u d ell P., Da u del1 R., Chemical Carcinogenesis and Molecular Biology, N. Y., 1966, p. 44.

8. Dipple A., Law ley P. D., B rookes P., Eur. J. Cancer, 4, 493 (1968).

9. Ш п ольски й Э. В., УФН, 71, 215 (1960); 77, 321 (1962); 80, 255 (1963).

10. С а ар и П., А в а р м а Р Р., Изв. АН ЭССР, Физ. Мат., 19, 115 (1971).

11. Friedel R. A., Orchin M., Ultraviolet Spectra of Aromatic Compounds, N. C., 1961.

12. D in er S., Electronic Aspects of Biochemistry, N. Y., 1964, p. 237.

Ннститут химии

Академии наук Эстонской ССР
Поступила в редакцию 10/X 1972 
M. GUBERGRITS, LIA PAALME, J. PAHAPILL

\section{MÕNEDE BENSO[a]PUREENI METUOLDERIVAATIDE FOTOINITSEERITUD DEGRADATSIOONI KINEETIKA}

Artiklis käsitletakse benso[a]püreeni metüülderivaatide fotodegradatsiooni kineetikat argooni ja hapniku atmosfääris. Kvaasijoon-fluorestsentsspektritest on määratud uuritud ühendite esimese ergastatud singletse oleku energia väärtus. Vesinikuaatomi asendamine benso[a püreeni molekulis ühe vôi kahe $\mathrm{CH}_{3}$ rühmaga suurendab degradatsiooni kiirust ja kvantsaagist, metüülderivaatide reaktsioonivõimelisus korreleerub molekuli ergastatud oleku energia väärtusega.

\section{GOUBERGRITS, L. PAALME, J. PAHAPILL}

\section{L'ETUDE CINETIQUE DE LA PHOTODEGRADATION DES CERTAINS DERIVES METHYLES DU BENSO[a]PYRENE}

L'article concerne les résultats d'une étude sur la cinétique de la photodégradation des certains derivés méthylés du benzo[a]pyrène dans l'atmosphère d'oxygène et d'argon et leurs spectres quasilinéaires d'excitation et de la fluorescence.

$\mathrm{La}$ reactivité des molecules du benzo[a]pyrène augmente avec le replacement d'hydrogène par les grouppes du méthyl. L'augmentation fixée de la reactivité des derivés methylés depend du nombre et de la disposition des substituents dans la molécule, et est en corrélation linéaire avec l'hauteur du premier singulet des hydrocarbures cancérogènes. 